\title{
Discurso intolerante e a rede social Instagram: uma análise de insultos e palavrões em comentários de seguidores
}

Júlio César Paula Neves julimgv@hotmail.com Universidade Federal de São João de Rei, São João del Rei, MG, Brasil.

\section{Aline Graciele Ferreira}

\section{alineferreira@ufsj.edu.br}

Universidade Federal de São João del Rei, São João del Rei, MG, Brasil.

\begin{abstract}
RESUMO
Considerando os modos de comunicação proporcionados pelas redes sociais, percebe-se que as pessoas interagem e se expressam por meio de postagens e comentários, e que isso, muitas vezes, se revela de forma violenta e intolerante. Amparados pelas contribuições teóricas de Barros (2007; 2011; 2016), Recuero (2009) e Charaudeau (2014), o objetivo geral deste artigo visa a compreender de que forma são construídos discursos intolerantes em comentários nas publicações do Instagram, mais precisamente, em 2017, na página do Deputado Federal Jair Bolsonaro, atual presidente do Brasil. Para atingir esse propósito, selecionamos quatro comentários para a análise; identificamos os discursos intolerantes; $\mathrm{e}$ descrevemos a construção desses discursos, tendo em vista os atos de fala e os contratos e estratégias de discurso. Observamos que os sujeitos, através da linguagem, expressam-se por meio de um discurso violento e intolerante para tratar de outros sujeitos que não pertencem ao seu corpo de práticas sociais e possuem princípios e convicções diferentes.
\end{abstract}

PALAVRAS-CHAVE: Rede Social. Instagram. Discurso Intolerante. 


\section{INTRODUÇÃO}

O crescente número de adeptos às novas tecnologias diz muito sobre a forma com que as pessoas vêm se comunicando e interagindo. Pode-se dizer que esse movimento tecnológico se apresenta como uma característica de uma sociedade que vê nesse tipo de instrumento uma nova forma de interação. Diante do cenário atual tecnológico, surgem, com mais frequência, novas redes sociais como Facebook, Twitter, Instagram, etc.

Para o presente trabalho, fizemos um recorte da página oficial do Instagram do ex-Deputado Federal e atual presidente da república Jair Bolsonaro ${ }^{1}$, na época, candidato à presidência do Brasil nas eleições do ano de 2018. A página de Bolsonaro, até 20/11/2017, contava com 671 mil seguidores e quase mil publicações. O ex-deputado alcançou popularidade nas redes sociais por suas pautas polêmicas sobre religião, negros, mulheres, homossexuais e o ultraconservadorismo. Trata-se de uma personalidade que faz parte de um grupo de extrema-direita no país e, com isso, tem um número expressivo de pessoas que se posicionam contra e a favor de seus pensamentos e indagações.

Como nossa pesquisa foi realizada no período em que se aproximava de um ano eleitoral, definimos como corpus deste trabalho dados de uma publicação realizada em 13/11/2017, no perfil de Bolsonaro. A publicação trata de uma pesquisa referente à eleição presidencial de 2018 que foi realizada em ManausAM, em novembro de 2017. Ela aponta que o candidato ocupava o segundo lugar de preferência de votos, ficando atrás apenas do ex-presidente da república, Luiz Inácio Lula da Silva. O conteúdo publicado conta com mais de 40 mil curtidas e quase 3500 comentários. Para este artigo, foram extraídos 4 comentários, nos quais serão analisadas as construções que nos possibilitam perceber os modos de composição que se configuram como discursos intolerantes e quais as estratégias linguístico-discursivas utilizadas para a percepção de tais constructos.

Em nossas análises, buscamos levar em conta as condições de produção histórico-ideológicas de cada enunciado, uma vez que tal materialidade linguíticodiscursiva pode ser vista como a reprodução exata/reverberação do ódio manifestado por uma postura antidemocrática, racista, misógina e preconceituosa do sujeito enunciativo Bolsonaro.

Como referencial teórico, nos amparamos em Barros (2016), ao tratar do discurso intolerante que circula na internet. Para a autora, a intolerância nesses espaços revela maior tonicidade e intensidade de alguns atributos da fala, potencializando discursos que circulam em sites de redes socias.

Para tratarmos dos contratos e estratégias de discurso, foram utilizadas as proposições de Charaudeau (2014), visto que o autor levanta discussões a respeito de indivíduos que pertencem a um mesmo corpo de práticas sociais e podem chegar a acordos sobre determinadas representações linguageiras de práticas sociais a que fazem parte. Charaudeau (2014) ainda trata das circunstâncias do discurso, ao retratar que tanto a produção quanto a interpretação de discursos dependem de elementos que circulam entre os indivíduos, por meio da linguagem.

Dessa forma, percorreremos caminhos que intentam a nos ajudar a compreender que prováveis atos realizados pelo, então, Deputado Federal Jair 
Bolsonaro provocaram esse fervor discursivo disposto nos enunciados. Como publicações nas redes sociais de Bolsonaro encorajam insultos e palavrões em comentários de seus seguidores.

\section{INTERNET, REDE SOCIAL E INSTAGRAM}

Segundo dados de uma pesquisa, o Brasil é o país que mais usa redes sociais da América Latina ${ }^{2}$. Com isso, a expansão da cobertura da internet, o aumento do uso das redes sociais e suas influências em vários segmentos da sociedade possibilitam um movimento de construção e desconstrução de valores e imagens e disseminação de ideias e ideais.

Partindo desse movimento, buscamos o conceito de "rede", em Castells (2005), em que, para o autor, uma sociedade em rede resulta da interação entre o paradigma da nova tecnologia e a organização social em um plano geral. Podemos pensar, então, a rede de internet e as redes sociais como uma ligação de fios e de conexões, formando um "elo" entre pessoas onde quer que elas estejam.

Ao tratarmos desse elo, consideramos a página do ex-deputado Jair Bolsonaro como ambiente onde pessoas com valores e ideais próximos se encontram. Tratase de um espaço onde podem ser encontradas materialidades linguístico-textuais de pessoas que comungam de determinados posicionamentos sócio-ideológicos.

A internet tem demonstrado ter, cada vez mais, um papel fundamental para que diversas figuras públicas interajam com o seu público. Podemos pensar que se trata de novas ferramentas, uma vez que essas pessoas se serviam principalmente de comunicações tradicionais como televisão, jornais impressos ou rádio para se comunicar em grande escala.

Junto com essas novas tecnologias, surgem formas de tratar de "democracia", de "liberdade de expressão". Pode-se dizer que esses espaços de discussões criados nas redes sociais também são palco de distorções de opiniões, crenças e valores, propagando, muitas vezes, divergências de ideias ou ideais, podendo carregar discursos de ódio. Barros (2016) discorre sobre esses discursos na internet:

Por isso, o discurso na internet tem seus sentidos exacerbados, já que engloba as possibilidades de interação das duas modalidades. Resultam daí sua interatividade intensa, a longa conservação de seus conteúdos e a grande extensão de seu alcance. Em outras palavras, ela dá maior tonicidade e intensidade a alguns atributos da fala, como a interatividade, e, ao mesmo tempo, aumenta a extensão e o alcance comunicacional da escrita. São essas as características de base dos discursos na internet -interatividade exacerbada, longa duração ou permanência dos discursos e grande extensão de seu alcance comunicacional e elas decorrem, principalmente, da complexidade entre a fala e a escrita, mas também de outras formações de termos complexos (público vs. privado, multibreagens, etc). Com isso, o discurso na internet permite e facilita a construção e a propagação de ondas de intolerância e, sobretudo, acentua a permanência, a 
extensão e o caráter passional e sensorial da intolerância. (BARROS, 2016, p. 12)

Em nosso estudo, a rede social pode se configurar como uma ferramenta profícua que nos permite analisar os comentários da página do Bolsonaro, o qual se revela como o político que lidera nas redes sociais quanto ao número de seguidores, de acordo com pesquisa da Zeeng ${ }^{3}$.

QUADRO 1 - Desempenho em redes sociais

\section{MILITÂNCIA VIRTUAL \\ Desempenho de pré-candidatos em redes sociais}

$\boldsymbol{7}$ No Facebook

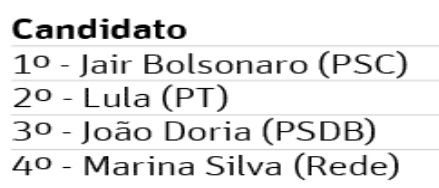

Seguidores

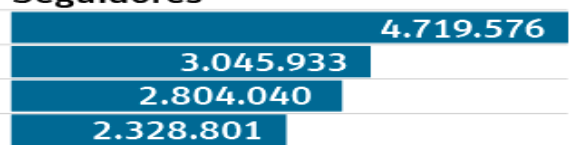

\section{Candidato}

10 - Jair Bolsonaro (PSC)

20 - Lula (PT)

30 - João Doria (PSDB)

40 - Ronaldo Caiado (DEM)

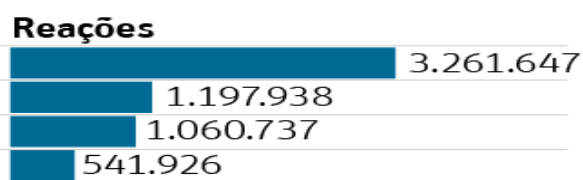

\section{No Twitter}

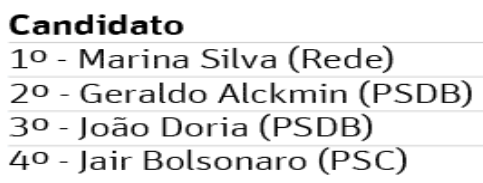

\section{Seguidores}

\begin{tabular}{|c|}
\hline 1.802 .306 \\
\hline 697.880 \\
672.640 \\
670.580
\end{tabular}

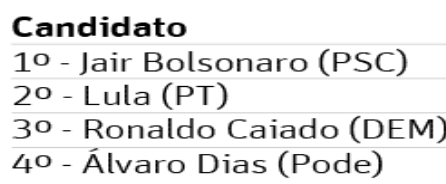

(0) No Instagram

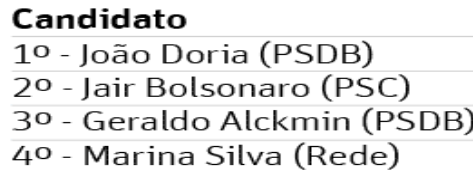

\section{Candidato}

10 - Jair Bolsonaro (PSC)

20 - João Doria (PSDB)

30 - Ronaldo Caiado (DEM)

40 - Lula (PT)

Curtidas

\begin{tabular}{|l|}
\hline \multicolumn{1}{|c|}{1.693 .030} \\
\hline 76.273 \\
|62.487 \\
| 1.00912 \\
do analisado: 23.set a 23.out.2017
\end{tabular}

Fonte: Zeeng Data Driven Plataform (2017)

Apesar de o atual prefeito da cidade de São Paulo estar em primeiro lugar no ranking do Instagram na notícia supracitada, nossa pesquisa aponta, com base na 
verificação desses números, que, no dia 20/12/2017, o deputado Jair Bolsonaro do (PSC) está ocupando o primeiro lugar no ranking, com mais de quinze mil seguidores à frente de João Dória.

Os dados acima citados podem ser compreendidos como possibilidade de aceitação ao posicionamento de Bolsonaro, uma vez que as pessoas tendem a seguir alguns perfis, com o intuito de acompanhar suas publicações. De acordo com Bakhtin (2006, p. 135), "compreender a enunciação de outrem significa orientar-se em relação a ela, encontrar o seu lugar adequado no contexto correspondente". Dessa forma, confirma-se a percepção de aceitação do posicionamento sócio-histórico-cultural de Bolsonaro por um grupo de pessoas, o que pode ser observado pela quantidade ou pelo aumento de seguidores de sua página nas redes sociais, sobretudo no Instagram.

Partindo do que se configura como rede social, para Recuero (2009, p. 24 apud Wasserman e Faust, 1994; Degenne e Forse, 1999): “Uma rede social é definida como um conjunto de dois elementos: atores (pessoas, instituições ou grupos; os nós da rede) e suas conexões (interações ou laços sociais)". Ainda para a autora:

\footnotetext{
Uma rede, assim, é uma metáfora para observar os padrões de conexão de um grupo social, a partir das conexões estabelecidas entre os diversos atores. A abordagem de rede tem, assim, seu foco na estrutura social, onde não é possível isolar os atores sociais e nem suas conexões. (RECUERO,2009, p. 24)
}

Dessa forma, é imprescindível, nos estudos de redes sociais, considerar os atores sociais (seguidores) como sujeitos que interagem e se expressam por meio dessas novas tecnologias, pois são esses sujeitos os responsáveis para que se formem essas conexões, configurando as interações de grupos sociais.

Ao apontar as proposições de Recuero (2009) sobre os atores sociais e suas conexões, nos questionamos se as vozes que emergem nos comentários com discurso intolerante se relacionam com as próprias questões sócio-ideológicas de Bolsonaro e se apresentam como réplicas. Bakhtin (2006, p. 135) discorre que:

A compreensão é uma forma de diálogo; ela está para a enunciação assim como uma réplica está para a outra no diálogo. Compreender é opor a palavra do locutor uma contrapalavra.

Assim, entendemos que, de alguma forma, como veremos nas análises, os enunciados produzidos pelos sujeitos que comentam nas publicações de Bolsonaro agem de forma responsiva e dialógica, por meio de réplica às publicações, reafirmando uma adesão ao posicionamento de Bolsonaro.

\section{A REDE SOCIAL INSTAGRAM E O DISCURSO INTOLERANTE}

São chamadas de redes sociais as páginas que possibilitam a criação de perfis com dados, vídeos e/ou fotos, viabilizando a amigos e outros seguidores a utilização do mesmo sistema, como o Instagram. 
Em nota lançada à imprensa ${ }^{4}$, os desenvolvedores do Instagram divulgaram a marca de 700 milhões de usuários ativos em abril de 2017, o que se apresenta como um número expressivo de pessoas que estão conectadas por esse meio de comunicação tecnológica. O Instagram é uma plataforma digital para smartphones, cuja função é a interação entre os usuários, que podem publicar fotos e pequenos vídeos. As pessoas conectadas a essa rede social têm acesso a contas de amigos, celebridades, políticos, marcas famosas e demais entidades as quais Ihes interessar, tendo a possibilidade de serem seguidores ou seguidos por essas páginas, o que dá acesso a diversos tipos de conteúdo e de postagens. Alguns optam por perfis abertos ao público, sendo possibilitado a outros usuários acesso ao conteúdo e às curtidas e comentários. Silva (2012) expõe a questão do modismo da rede social citada:

O Instagram está na moda expondo consigo o ponto de vista da intimidade, das relações de consumo, das experiências do sujeito. Tal exposição pressupõe uma espera ou conviç̧ão na promessa de ser visto, não ser esquecido. Algo muito parecido quando pensamos em uma dimensão biográfica para as narrativas contemporâneas. (SILVA, 2012, p. 6)

A partir do nosso contato com essa rede social, observamos que, nos comentários, podem circular discursos intolerantes, que se apresentam de forma violenta e caracterizam alguns sujeitos, colocando-os em posição desprivilegiada, punitiva e marginalizada, punindo-os por sua conduta e preceitos. Para Barros (2007), esses tipos de discursos têm relação com as formas de intolerância:

A relação estreita entre as várias formas de intolerância (racial, religiosa, social, política, socioeconômica, linguística) é, sem dúvida, uma das características gerais dos discursos intolerantes. Essas relações são geralmente hierarquizadas, ou seja, há uma forma de intolerância de base, predominante, a que se subordinam as demais, como, por exemplo, ocorre no Brasil no caso do preconceito racial em relação aos negros, que pode ser considerado uma intolerância primária, em relação às intolerâncias quanto ao modo de falar dos negros, à sua religião, etc. (BARROS, 2007, p. 148)

Isso nos faz perceber que essas formas de intolerância circulam nas redes sociais, caracterizando-se como discursos intolerantes entre grupos, o que pode revelar traços dessas relações hierarquizadas. No caso do corpus selecionado para a nossa análise, percebemos que certo tipo de intolerância política está muito presente nos comentários, uma vez que percebemos um embate entre posições partidárias, o que pode representar posicionamentos contrários, que emergem de uma questão responsiva e dialógica (BAKHTIN, 2006), como discutido anteriormente.

Pensando nas diversas possibilidades de percepções dos sujeitos que interagem nesses espaços, notamos que a criação de novas redes sociais faz com que as pessoas, muitas vezes, não consigam discernir entre a noção de público e privado. Isso se revela de forma com que os discursos intolerantes vêm sendo declarados como possível liberdade de expressão. Com a expansão da internet e 
das redes sociais, pode-se perceber um movimento em que esses discursos se apresentam com maior visibilidade e frequência, revelando sujeitos intolerantes.

Conforme Barros (2007, p. 146-147), os discursos desses sujeitos surgem a partir de duas etapas: a primeira, de forma que o sujeito se apresenta de modo malevolente em relação a outro sujeito de posições contrárias e benevolente em relação aos iguais; a segunda etapa se refere ao sujeito preconceituoso, com ódio, frustrado ou inseguro que passa a agir contra esse outro de posições contrárias às suas. Assim sendo, tais etapas nos permitem visualizar algumas características desses sujeitos que circulam nas redes sociais, ou remetendo a Bakhtin (2006), por meio de uma ação responsiva. Essas particularidades, em nosso trabalho, são percebidas a partir da materialização desses comentários intolerantes, malevolentes ou preconceituosos em relação a outros sujeitos, o que será apresentado, mais à frente, na análise do corpus selecionado.

\section{ATOS DE FALA E OS CONTRATOS E ESTRATÉGIAS DE DISCURSO}

As formulações de Charaudeau (2014) apontam para a desconstrução de uma ideia resistente em nossa sociedade, que é a premissa da comunicação como fenômeno de transmissão intencional de informação. O autor, ao tratar das circunstâncias do discurso, explora um universo em que tanto a produção quanto a interpretação de discursos dependem de elementos e saberes que circulam entre os protagonistas da linguagem. Isso se revela a partir de seus estudos sobre os atos de linguagem e a forma como a interação entre os sujeitos é construída a partir de contratos e de estratégias. Para Charaudeau (2014, p. 44), definir as circunstâncias do discurso depende dos saberes supostos que circulam entre os protagonistas da linguagem, e a partir de uma dupla dimensão entre o explícito/implícito do fenômeno linguageiro.

Ao tratarmos desses sujeitos, faz-se necessário compreender a divisão que Charaudeau (2014) faz da situação de comunicação, dividindo os sujeitos em quatro: EUc - sujeito comunicante (ser social); EUe - sujeito enunciador (ser de fala); TUd - sujeito destinatário (ser de fala); e o receptor TUi - que é o sujeito interpretante (ser social). A presença desses sujeitos será explicitada de forma mais clara na análise do nosso corpus. Doravante, usaremos apenas as siglas EUc, EUe, TUd e TUi para nos referirmos a esses sujeitos, a fim de facilitar a compreensão da análise.

Partindo para a noção de contrato apresentada por Charaudeau (2014), podemos entender um tipo de interação pela busca de acordos em que:

A noção de contrato pressupõe que os indivíduos pertencentes a um mesmo corpo de práticas sociais estejam suscetíveis de chegar a um acordo sobre as representações linguageiras dessas práticas sociais. Em decorrência disso, o sujeito comunicante sempre pode supor que o outro possui uma competência linguageira de reconhecimento análoga à sua. Nesta perspectiva, o ato de linguagem torna-se uma proposição que o EU faz ao TU e da qual ele espera uma contrapartida de conivência. (CHARAUDEAU, 2014, p. 56) 
É pela noção de contrato que se revelam as similaridades entre os sujeitos e o reconhecimento de um possível acordo a partir de especificidades que os unem como, por exemplo, aspectos ideológicos, religiosos, culturais, entre outros.

Já o conceito de estratégia para Charaudeau (2014) se insere na forma de organização do discurso com vista a produzir certos efeitos de sentido e a atingir algum objetivo, ou seja:

A noção de estratégia repousa na hipótese de que o sujeito comunicante (EUc) concebe, organiza e encena suas intenções de forma a produzir determinados efeitos de persuasão ou de sedução de modo consciente ou não - com o sujeito destinatário ideal (TUd) construído por EUc. (CHARAUDEAU, 2014, p. 56)

Com isso, podemos observar que tanto pela noção de contrato quanto pela noção de estratégia os quatro sujeitos propostos por Charaudeau (2014) desempenham papéis distintos no que diz respeito aos atos de linguagem. Serão nessas duas perspectivas que nos apoiaremos para o desenvolvimento de nossa análise. Esses conceitos são fundamentais para buscarmos compreender de que forma se revelam os sujeitos que circulam nas redes sociais, e de que forma os contratos e estratégias apresentados em forma de comentários se configuram como discurso intolerante.

\section{ANÁLISE DE COMENTÁRIOS: INSULTOS E INTOLERÂNCIA NO INSTAGRAM}

Ao elaborar este trabalho, estávamos entrando no ano em que ocorreram novas eleições presidenciais, e esse fato começou a tomar espaço na mídia e nas redes sociais. Trata-se de um período em que começam a surgir os possíveis candidatos, e, junto com eles, apareceram aquelas pessoas que simpatizam com suas propostas e prerrogativas ou refutam-nas. Com todo esse movimento eleitoral, algumas pessoas buscam expressar suas posições partidárias de diversas formas.

Vale ressaltar, que, esta pesquisa foi realizada anteriormente ao resultado das eleições. Portanto, alguma questões sócio-histórico-ideológicas não são abordadas, de forma bem marcadas, visto que algumas dessas questões tomaram proporções mais pontuais após a posse do presidente eleito.

Temos, na imagem abaixo, o resultado de uma pesquisa realizada na cidade de Manaus - AM publicada na página do Instagram do, então, Deputado Federal Jair Bolsonaro. Na pesquisa divulgada pelo próprio candidato, ele aparece em segundo lugar no ranking dos possíveis concorrentes à presidência do Brasil. Possíveis, uma vez que ainda não havia sido divulgada a lista com os nomes que, de fato, iriam fazer parte dessa disputa. 


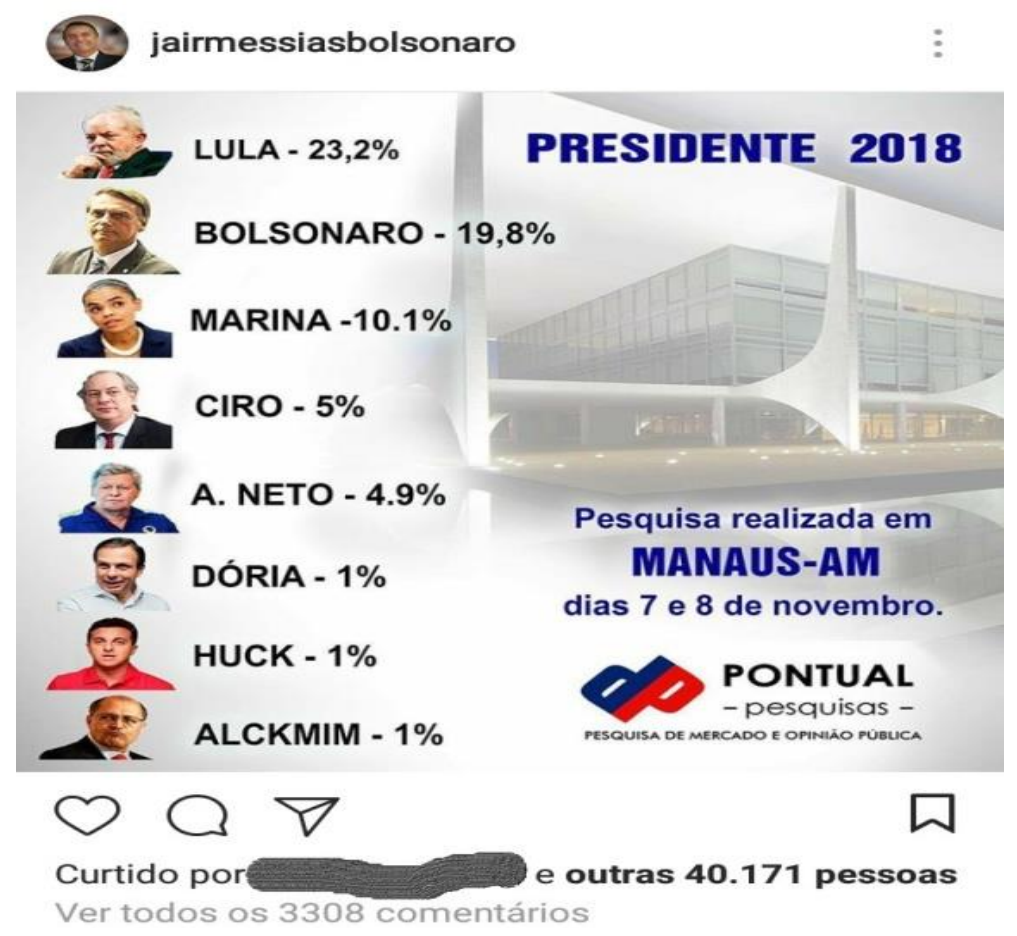

Fonte: Instagram (2017)

Ao se tratar de uma rede social que comporta comentários e curtidas (ferramentas que os seguidores podem utilizar para se posicionar quanto ao conteúdo transmitido), a imagem publicada no dia 13/11/2017 apresentou, até o dia 07/12/2017, mais de quarenta mil curtidas e mais de três mil comentários. A partir de uma análise detalhada, observamos que a maioria desses comentários vem de pessoas simpatizantes com os posicionamentos de Bolsonaro. $\mathrm{O}$ que nos inquietou foi perceber a forma agressiva e intolerante de se posicionar politicamente contra um adversário, visto que a disputa política pressupõe a diversidade de propostas para a sociedade. Desse modo, o discurso de ódio parece destoar dos pressupostos do jogo. Amparados nas premissas de Charaudeau (2014), buscaremos compreender a construção discursiva desses comentários que se configuram como um discurso intolerante.

FIGURA 2: Comentário 1

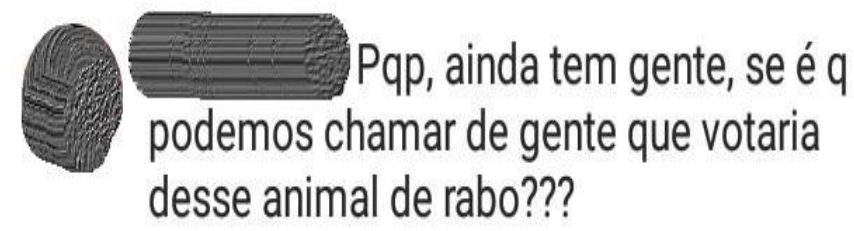

Fonte: Instagram (2017)

Ao iniciar a análise do primeiro comentário, devemos levar em consideração o que Charaudeau (2014) considera por circunstâncias do discurso em que o ato de linguagem tanto como evento de produção ou de interpretação depende dos 
saberes supostos que circulam entre os sujeitos envolvidos, no caso, a página de um político de extrema-direita, possível candidato à presidência da república e com seguidores que se filiam aos seus pensamentos e suas proposições.

Podemos dizer que está presente nesse comentário um EUc responsável pelo ato de produção do comentário e que se apresenta como um EUe que é um ser de fala. Esse Eu-enunciador constrói uma imagem de alguém com um discurso intolerante, uma vez que se refere ao candidato de oposição como "animal de rabo", de modo que, pela nossa interpretação, podemos supor que ele utiliza dessa estratégia para desumanizar e escarnecer de um candidato de forma violenta, inclusive, trata-se de uma animalização do candidato. Isso ainda se assemelha ao que Charaudeau (2014, p. 57) trata por "fabricação de uma imagem de ficção como lugar de identificação do sujeito com um outro, imagem esta que constitui um lugar de projeção do imaginário desse sujeito", ou seja, uma forma punitiva e ficcional de tratar o outro de que se fala.

A partir desse primeiro comentário, consideramos as condições históricas e ideológicas que poderiam provocar o aparecimento desses discursos na página de Bolsonaro. Entendemos que existe um descontentamento dessas pessoas que comentaram, quanto ao governo anterior, regido pelo Partido dos Trabalhadores (PT).

Podemos ainda comentar sobre a expressão "Pqp" (puta que pariu), muito utilizada para indicar certo tipo de indignação, no caso do comentário, a posição do político de oposição partidária em primeiro lugar no ranking dos candidatos.

FIGURA 3 - Comentário 2

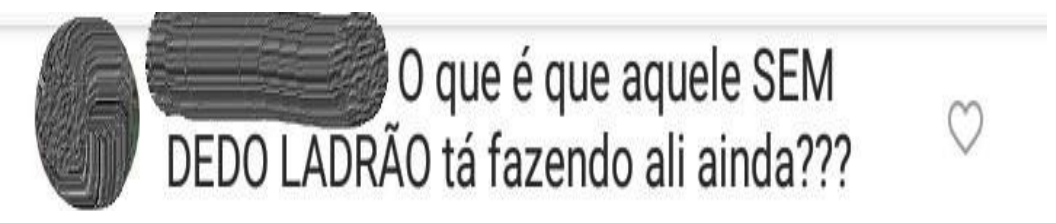

Fonte: Instagram (2017)

Partindo do pressuposto de que todos os elementos presentes na página do Bolsonaro são constitutivos do discurso, e fletem um posicionamento sóciohistórico-ideológico, podemos dizer que circula nessa página um tipo de contrato discursivo. É a noção de contrato apresentada por Charaudeau (2014) que nos permite supor um fluxo de indivíduos pertencentes a um mesmo corpo de práticas sociais, o que gera um movimento de reconhecimento e responsividade (Bakhtin, 2016), e faz não com que esses sujeitos refutem os modos de intolerância uns dos outros, mas que, de certa forma, sejam coniventes, e reforcem com o que é colocado nos comentários. Isso se aproxima do que Silva (2012) apresenta como característica das redes sociais, uma vez que se trata de um lugar em que os sujeitos expõem seu ponto de vista, e, neste caso, pontos de vista amparados por um tipo de contrato comunicacional.

Como marcas de intolerância no segundo comentário, destacamos o excerto em caixa alta "SEM DEDO LADRÃO" em que revela um EUe que se refere ao candidato de oposição de forma violenta, dando ênfase a suas características 
físicas como deformidade e imperfeição, uma vez que o ex-presidente Luiz Inácio Lula da Silva, do Partido dos Trabalhadores, é conhecido por ter um dedo a menos em função de um acidente. Dessa forma, podemos associar ao que Barros (2011) apresenta como um discurso de sanção que se refere aos sujeitos considerados como maus cumpridores de certos contratos sociais e que são punidos de alguma forma.

FIGURA 4 - Comentário 3

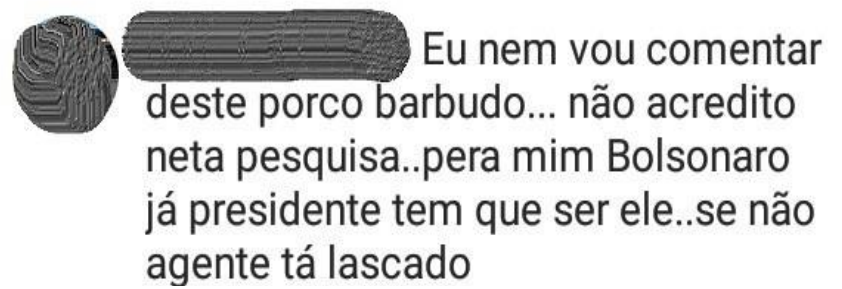

Fonte: Instagram (2017)

No terceiro comentário também encontramos formas de insultos e xingamentos como a expressão "porco barbudo", remetendo ao candidato Luís Inácio Lula da Silva. Pode-se dizer que se tem um padrão de animalização, o que parece ser característica de discursos intolerantes, visto que inferiorizam ou desumanizam o outro. Isso ocorre pela negação ou não adesão ao posicionamento político e ideológico do candidato. No trecho "não acredito nesta pesquisa", podemos afirmar que, a partir do ato de linguagem, se apresenta um EUc que constrói a imagem de um TUd "ideal" capaz de concordar com a premissa de uma pesquisa que pode conter falhas em seus dados. Tal asserção do sujeito comentante corrobora com os posicionamentos de Bolsonaro, uma vez que este aponta em seus discursos para um desmerecimento e descrédito de pesquisas e outras fontes de circulação tidas como confiáveis. Essa possível interação entre os sujeitos e as asserções do proprietário da página, Bolsonaro, se configura ao que Recuero (2009) desenvolve acerca da noção de rede como uma metáfora para observar os padrões de conexão de um grupo social, ou seja, alguém que, possivelmente, fala para seus semelhantes (seguidores do Bolsonaro).

Já o trecho "senão a gente tá lascado", reflete a noção de estratégia, uma vez que, segundo Charaudeau (2014, p. 56) "o sujeito comunicante (EUc) concebe, organiza e encena suas intenções de forma a produzir determinados efeitos de persuasão ou de sedução - sobre o sujeito interpretante (TUi)". O trecho destacado se apresenta em forma de reforçar, de demonstrar a indignação a um TUi para levá-lo a se identificar com a hipótese de que, se Bolsonaro não ganhar as eleições presidenciais de 2018, eles irão perecer. 
FIGURA 5 - Comentário 4

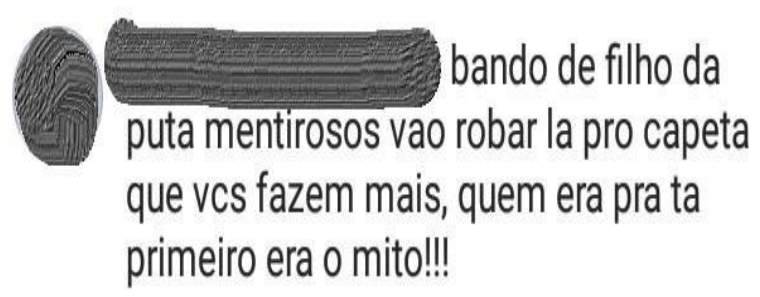

Fonte: Instagram (2017)

No quarto e último comentário de nossa análise, encontramos vários trechos com palavras grosseiras e ofensivas como: "bando de filho da puta", "mentirosos" e "vão roubar lá pro capeta que vocês fazem mais" que se caracterizam como um discurso intolerante. Pode-se dizer que as marcas de intolerância se inscrevem, desta vez, não diretamente a um político, mas ao grupo que realizou a pesquisa e, possivelmente às pessoas que se filiaram aos outros candidatos concorrentes ao cargo de presidente da república.

Outro recorte presente no comentário é a expressão "mito", muito utilizada pelos seguidores do Bolsonaro para se referir ao ex-deputado. Segundo definição do dicionário, o termo mito, além de outras definições, significa "Coisa ou pessoa fictícia, irreal; ideia falsa, que distorce a realidade ou não corresponde a ela" (2000, p. 466). Partindo das proposições de Charaudeau (2014) quanto à imagem de fiçcão como lugar de identificação, pode-se dizer que se constitui aí um lugar de projeção do imaginário de um sujeito (Bolsonaro), uma vez que ele é colocado em uma posição de alguém que, de uma forma "irreal" ou "imaginária", tem a capacidade de governar o país com maestria e surge de maneira salvadora.

Dessa forma, podemos refletir sobre posicionamentos que, para conduzir alguém a uma posição elevada, desprivilegiam seus concorrentes de forma violenta e intolerante, muitas vezes usando de estratégias como animalização e ofensas. Isso pode se caracterizar como uma forma de punir um sujeito com o intuito de elevar outro.

\section{CONSIDERAÇÕES FINAIS}

Dado o exposto, observamos uma regularidade nos comentários analisados em que o sujeito comunicante EUc projeta um sujeito enunciador Eue que possui um discurso intolerante e composto por marcas violentas. Isso ocorre na forma de insultos e ofensas a respeito de um candidato de oposição política e ideológica. Tais ofensas e insultos se configuram, conforme apresenta Barros (2007), como um discurso de sansão em que se busca punir alguém.

Trabalhando aqui as duas etapas dos percursos passionais do sujeito intolerante, estudados por Barros (2007), notamos uma maior visibilidade desses sujeitos no que, para ela, seria a segunda fase dos percursos, a intolerância propriamente dita. Os sujeitos comentaristas da publicação de Bolsonaro, frustrados ou com ódio, passam a agir contra o outro, aqui no caso o ex-presidente Lula, quando se utilizam de palavras ofensivas e pejorativas como "animal sem rabo", "sem dedo", "ladrão", "porco rabudo", deixando a entender sua preferência política, naquele momento, por Jair Bolsonaro. 
Segundo as discussões de Bakhtin (2006, p. 135), consideramos que a significação por meio dos comentários com discurso intolerante pertence a uma ideia responsiva de "identificação enquanto traço de união entre os interlocutores, isto é, ela só se realiza no processo de compreensão ativa e responsiva", o que aponta para um reconhecimento de posicionamentos políticos, sociais e ideológicos do político de sua preferência, no caso, Jair Bolsonaro.

Por fim, percebemos que é por meio de contratos e de estratégias linguísticodiscursivas que esses discursos intolerantes são construídos e é a linguagem que possibilita aos sujeitos se expressarem e defenderem seu ponto de vista dentro das redes sociais, especificamente, no Instagram, de onde coletamos o nosso corpus. Podemos ainda dizer que, devido ao percurso de nosso trabalho, foi possível perceber de que forma se constroem ou se configuram os discursos intolerantes nos comentários, e que esse processo depende dos sujeitos para sua construção. 


\title{
Intolerant speech and the social network Instagram: an analysis of insults and bad words in followers' comments
}

\begin{abstract}
Considering the means of communication provided by social networks, it is noticed that people interact and express themselves through posts and comments, that are often appear as violent and intolerant. Based on the theoretical contributions of Barros (2007; 2011; 2016), Recuero (2009) and Charaudeau (2014), the main goal of this article is to understand how intolerant discourses constructed in Instagram publications are, in 2017, specially at the page of the congressman Jair Bolsonaro, current president of Brazil. To achieve this purpose, we have selected four comments for this analysis. We identified intolerant discourses; and we describe the construction of these discourses in light of speech acts and the contracts and strategies of discourse. Finally, we have observed that the subjects, through language, express themselves through a violent and intolerant discourse to deal with other subjects that do not belong to their body of social practices and have different principles and convictions.
\end{abstract}

KEYWORDS: Social Network. Instagram. Intolerant Speech. 
${ }^{1}$ Instagram. Jair Bolsonaro (jairmessiasbolsonaro). Disponível em: https://www.instagram.com/p/Bbcq3 5Dzoe/?hl=pt-br\&takenby=jairmessiasbolsonaro. Acesso em: $20 \mathrm{dez} .2017$.

${ }^{2}$ Brasil é o país que mais usa redes sociais da América Latina. Disponível em: https://canaltech.com.br/redes-sociais/brasil-e-o-pais-que-mais-usa-redessociais-na-america-latina-70313/. Acesso em: 10 dez. 2017.

${ }^{3}$ Plataforma de dados voltada para marketing e comunicação. Disponível em: http://www1.folha.uol.com.br/poder/2017/11/1938138-bolsonaro-liderainfluencia-nas-redes-sociais-aponta-pesquisa.shtml. Acesso em 16 dez. 2017.

${ }^{4}$ Disponível em: http://tecnologia.ig.com.br/2017-04-28/instagram-emnumeros.html. Acesso em: 20 nov. 2017.

${ }^{5}$ PAIL, Daisy Batista. A retórica da polidez e dos palavrões nas redes sociais: uma abordagem por interfaces. Dissertação de Mestrado, Instituto de Letras, PUCRS, 2012.

\section{REFERÊNCIAS}

BAKHTIN, M. M. (VOLOCHINOV). Marxismo e filosofia da

linguagem. Problemas fundamentais do método sociológico na ciência da linguagem. Trad. Michel Lahud e Yara Frateschi Vieira. 12. ed. São Paulo: Hucitec, 2006 [1929].

BARROS, D. L. P. de. A identidade intolerante no discurso separatista. In. Filologia e Linguística portuguesa, $n^{\circ}$ 9, p. 147-167. São Paulo: USP, 2007.

A construção discursiva dos discursos intolerantes. In: BARROS, D. L. P. de. Preconceito e intolerância. Reflexões linguístico-discursivas. p.255-270. São Paulo: Editora Mackenzie, 2011. 
. Estudos discursivos da intolerância: o ator da enunciação

excessivo. In: Cadernos de Estudos Linguísticos, v. 58, n. 1, p. 7-24.

Campinas: Unicamp, 2016.

CASTELLS, Manuel; CARDOSO, Gustavo (Orgs.). A Sociedade em Rede: do conhecimento à ação política; Conferência. Belém (Por): Imprensa Nacional, 2005.

CHARAUDEAU, Patrick. Linguagem e discurso: modos de organização / Patrick Charaudeau; [coordenação da equipe de tradução Angela M. S. Corrêa \& Ida Lúcia Machado]. - 2. ed., $2^{\mathrm{a}}$ reimpressão - São Paulo:

Contexto, 2014.

FERREIRA, Aurélio B. de H. Mini Aurélio Século XXI Escolar. O minidicionário da língua portuguesa. Rio de Janeiro: Nova Fronteira, 2000 .

OLIVEIRA, Y. R. O Instagram como Uma Nova Ferramenta para Estratégias Publicitárias. In: Intercom. São Paulo: Intercom - Sociedade Brasileira de Estudos Interdisciplinares da Comunicação. v. 16. p. 1-13. 2014.

RECUERO, Raquel. Redes Sociais na Internet. Porto Alegre: Sulina, 2009.

SILVA, Polyana I. R. Dinâmicas comunicacionais na vida cotidiana Instagram: um modo de narrar sobre si, fotografar ou de olhar pra se ver. In: XVII Congresso de ciências da comunicação na região sudeste, 2012, Ouro Preto. Artigo Científico. Ouro Preto: Intercom - Sociedade Brasileira de Estudos Interdisciplinares da Comunicação, 2012. 
Recebido: 25 fev. 2020

Aprovado: 04 mar. 2020

DOI: $10.3895 /$ rl.v22n36.9664

Como citar: NEVES, Júlio Cesar Paula; FERREIRA, Aline Graciele. Discurso intolerante e a rede social instagram: uma análise de insultos e palavrões em comentários de seguidores. R. Letras, Curitiba, v. 22, n. 36 p. 84-100, mar. 2020. Disponível em: <https://periodicos.utfpr.edu.br/rl>. Acesso em: XXX.

Direito autoral: Este artigo está licenciado sob os termos da Licença Creative Commons-Atribuição 4.0 Internacional.

(c) (1) 